\title{
AN UNUSUAL CAUSE OF TESTOSTERONE DEFICIENCY
}

\section{Eboh ; P. Price ; L . Moorhouse Great Western Hospital , Swindon.}

\section{BACKGROUND}

"Nutritional supplements" are easily available online and can be purchased from some sports nutrition shops. They are widely used especially in the body building community

CASE

36 year old gentleman referred by his GP with poor libido and erectile dysfunction .

No other symptoms of hypogonadism or of pituitary disease. . Previously fit and well. Teetotal . On no medication. Patient an avid fitness fanatic. He had never knowingly used anabolic steroids. However, he had taken a 'nutritional supplement' called TBullets (purchased from a sports nutrition shop to improve his gym performance) for 20 days until just before GP's referral. Examination revealed a well virilised gentleman with no signs of hypogonadism.

\section{RESULTS}

9 AM Testosterone $-0.3 \mathrm{nmol} / \mathrm{L}(10-35)$

LH $\quad-<0.2$ IU/L (2-18)

FSH - $0.1 \mathrm{IU} / \mathrm{L}(1-16)$

9 AM Cortisol - 457 nmol/L (138-690)

Free T4 - $11 \mathrm{pmol} / \mathrm{L}(5.6-21)$

Prolactin - $71 \mathrm{mIU} / \mathrm{L}(50-500)$

IGF-1 - $331 \mu \mathrm{g} / \mathrm{L}$ (75-344).

MRI Pituitary \& Hypothalamus within normal limits

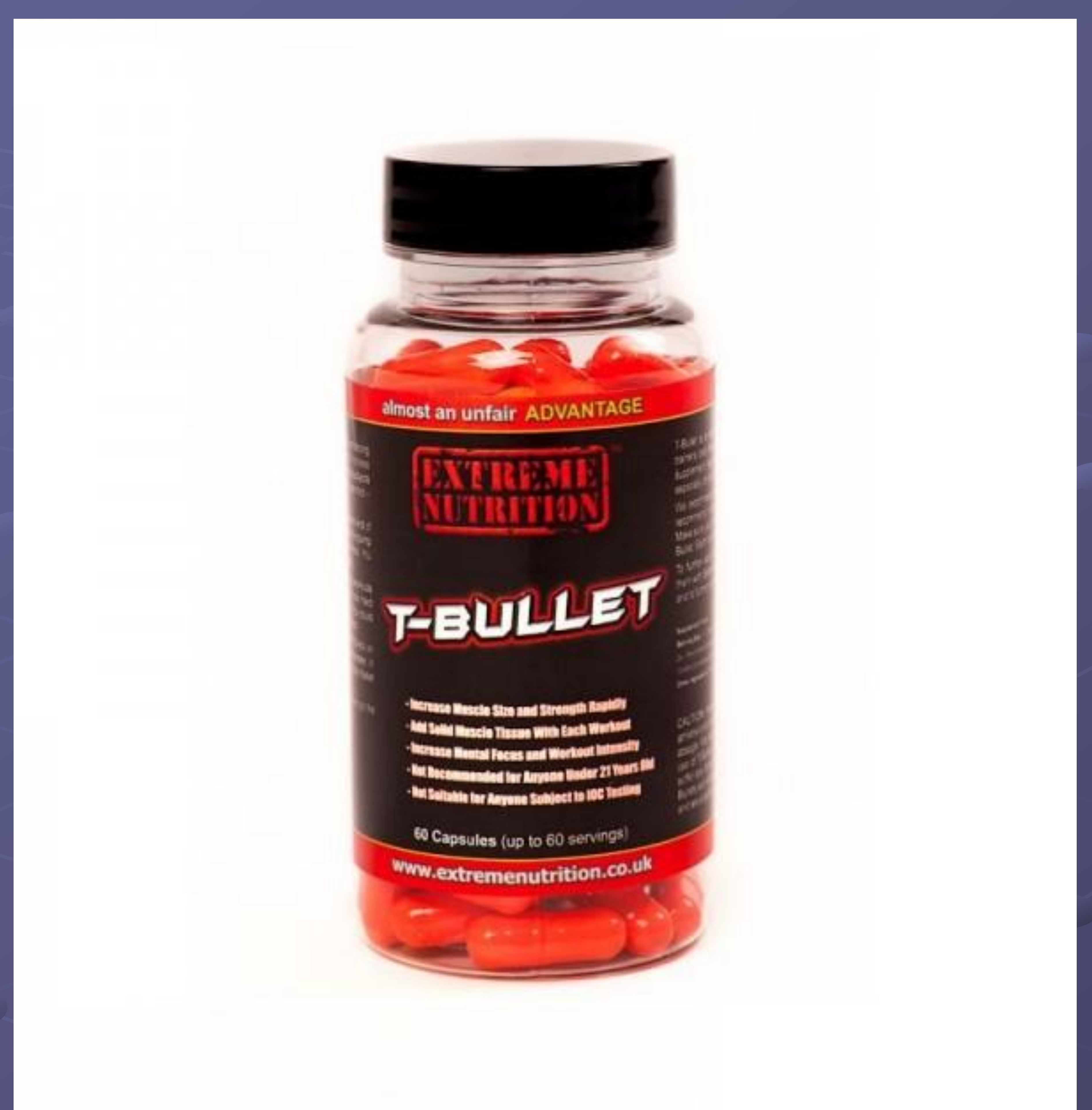

RESULTS ( 6 MONTHS LATER )

9 AM Testosterone

04/10/12 - $6.9 \mathrm{nmol} / \mathrm{L}$

29/10/12 - $10 \mathrm{nmol} / \mathrm{L}$

\section{DISCUSSION}

T -Bullets are marketed as "nutritional supplements" by the makers. The active ingredient is: "2a, 17a-dimethy-5a-androst-3one-17b-ol 13-ethyl-3-methoxy-gona-2,5,(10)dien-17-one" which Martindale:The complete drug reference lists as an anabolic steroid (related to testosterone)

Anabolic steroids were first artificially synthesized in the 1930s. The misuse of anabolic steroid drugs to enhance physique, body strength and athletic performance is wellknown. Use of anabolic steroids can result in hypogonadotrophic hypogonadism as a result of suppression of the hypothalamo-pituitarygonadal axis (HPG). While the suppression of the HPG axis induced by anabolic steroids is reversible, it may persist for several months or more following withdrawal of the steroid. ${ }^{1-3}$ In this case, it took 6 months for recovery of the HPG axis.

\section{CONCLUSION}

The unwitting consumption of an anabolic steroid should be considered in any patient presenting with hypogonadotrophic hypogonadism who has been taking a "nutritional supplement".

REFERENCES

Bagatell CJ, Bremner WJ. Androgens in men - users and abusers. New Engl and Journal of Med 1996;334:707-14.

2 Lamb DR. Anabolic steroids in athletics: how well do they work and how dangerous are they? Am Jf Sports Med 1984; 12:31-8. rry HM, Littlepage BNC. Misusing anabolic drugs. BMJ 